\title{
Grid Integration as a Strategy of Med-TSO in the Mediterranean Area in the Framework of Climate Change and Energy Transition
}

\author{
Antonio Moretti ${ }^{1}$, Charalampos Pitas ${ }^{2, *}$, George Christofi ${ }^{3}$, Emmanuel Bué ${ }^{4}$ \\ and Modesto Gabrieli Francescato ${ }^{5}$ \\ 1 Association of the Mediterranean TSOs (Med-TSO), Viale Egidio Galbani, 70, 00156 Rome, Italy; \\ antonio.moretti@med-tso.com \\ 2 Independent Power Transmission Operator (IPTO/ADMIE) SA, 89 Dyrrachiou Str., 10443 Athens, Greece \\ 3 Transmission System Operator of Cyprus (TSOC), 68 Evagelistrias Str., 2057 Strovolos, Nicosia, Cyprus; \\ gchristofi@dsm.org.cy \\ 4 Réseau de Transport d'Electricité (RTE), 7C place du Dôme, 92800 Puteaux, Paris, France; \\ emmanuel.bue@rte-france.com \\ 5 Terna S.p.A.-Rete Elettrica Nazionale, Viale Egidio Galbani, 70, 00156 Roma, Italy; \\ modesto.gabrielifrancescato@terna.it \\ * Correspondence: c.pitas@admie.gr; Tel.: +30-210-519-2238
}

Received: 10 August 2020; Accepted: 2 October 2020; Published: 12 October 2020

check for updates

\begin{abstract}
The paper presents a survey on the situation in terms of solutions for grid integration throughout the Mediterranean area in the framework of climate change and energy transition. The objective of the study is focused on Mediterranean region connectivity initiatives in the context of the broader vision of an interconnected European-Mediterranean (Euro-Med) power system for a future low-carbon energy system as the fundamental objective of Med-TSO, the Association of the Mediterranean Transmission System Operators (TSOs) for electricity. The analysis examines how the power grid connectivity evolves from now on to 2030, describing the progress made to date in integrating the power grids of the Mediterranean region as well as the future possibilities for a more integrated power grid covering the whole region. The research, conducted within Mediterranean Project II of Med-TSO, includes an overview on the current situation of the interconnections and the proposal for the 2030 interconnections Master Plan, coherent with the national development plans (NDPs) and shared energy scenarios for the whole region at the same horizon of 2030. It conducts an assessment of the gap between the current and the 2030 expected situation, taking into account the energy transition toward 2030 objectives resulting from the achievements of climate change pledges, local governmental policies and EU strategy for neighboring countries and Africa. The solutions survey includes technical solutions, procedures and rules to improve systems' integration and increase regional electricity exchanges in Med-TSO countries, and is aimed at achieving a higher quality of services and better efficiency of energy supply in Med-TSO member countries in the framework of the expected energy transition. The main scope is to present solutions that will be made available due to maturity and experience in the coming decade, specifically: high voltage direct current (HVDC) transmission technologies, energy storage, sectors coupling, smart grid technologies and services, inter-TSO and transmission-distribution cooperation platforms, etc. The article presents two case studies: the island paradigm and a new cross-border interconnection project of common interest. Finally, the post-pandemic core role of TSOs, which has become more relevant than ever, is transformed into a key-enabler of energy transition towards a sustainable, resilient and innovative climate-neutral recovery.
\end{abstract}


Keywords: mediterranean region; grid integration; climate change; energy transition; cross border interconnections; technical solutions

\section{Introduction}

Climate change is becoming a more and more tangible issue and the increased public awareness is resulting in a greater attention from global media, governments and the corporate world. Climate change has become a top priority of our time and making the transition to a carbon neutral economy is increasingly considered as a must. The energy transition towards a carbon neutral economy is a necessity in order to achieve sustainable growth that is in line with the core of the seventeen Sustainable Development Goals (SDGs) affiliated with the UN through the 2030 Agenda [1].

The growing concerns about the effects of the climate change have pushed governments to adopt appropriate but contrasting policies that all refer to the fundamental Paris Agreement [2]. The Paris Agreement demonstrates a roadmap to reduce global temperature increments to "well below $2{ }^{\circ} \mathrm{C}$ ", and ideally to $1.5^{\circ} \mathrm{C}$, which is comparable to pre-industrial levels.

The successful limitation of climate change impacts requires a thorough transformation of the global energy landscape based on a swift development of low-carbon solutions instead of typical fossil fuel power generation and uses. To upscale the energy transition at the needed rate and level would require more or less a total decarbonisation of the electricity sector by 2050 [3], for which scaling up electricity production from renewable energy sources (RES) will be crucial and urgent. In this sense, the most important drivers are the augmenting low-cost of RES technologies and the broader espousal of electricity for end-use utilization in transportation and heating.

One of the most aggressive global scenarios for tackling this challenge is that developed by the International Renewable Energy Agency (IRENA) [4]. According to this agency, in order to reach the targets of the Paris Agreement, $\mathrm{CO}_{2}$ emissions from energy should to be decreased by around $3.5 \%$ each year up to 2050, with thereupon continued reductions. Out of this particular scenario, a range of future scenarios of European power grids are based on wide wind and solar shares to meet the aspiring $\mathrm{EU} \mathrm{CO}_{2}$ emission reduction targets.

World-leading strategies for reducing greenhouse gases include a full use of renewable resources while maintaining an efficient, reliable and affordable energy grid. This implies a significant increase in variability in the electricity supply and the consequent need to have more flexibility available in the system in order to balance the related effects. Different flexibility options are available to improve the energy system's flexibility, including an increased participation by energy storage resources, utilization of the demand response mechanism to enable adjustments in consumer demand, both up and down, transmission expansion, interconnection and regional integration, sectors coupling of power to gas as well as power to heat.

Generally speaking, close cooperation on the regional level as well as a good level of energy exchanges and a high level of physical interconnection help to increase balancing effects. Two concepts are widely used to balance the variable renewable sources: balancing at continental land scales using the transmission system, as well as locally with energy storage.

The importance of developing regional grid interconnections in support of sustainable development is widely recognized. The concept of cross-border power grid connectivity has gained increasing support from states and international organizations, given the benefits it can offer in lowering costs, mutualizing generation and balancing capacity, diversifying supply, and helping the deployment of the renewable and low carbon energy resources. Interconnected multi-country power grids are increasingly seen as an enabler for renewable energy, and as such a means to help achieve the agreed upon goal of sustainable energy. There is an increased global focus on developing cross-border power interconnection to promote the electricity trade between countries and regions and to foster the integration of electricity markets. 
The prospect to interconnected and interoperated power grids that have reciprocity in terms of electricity characteristics (e.g., load profile, generation mix) in a more integrated way is an added value with direct implications for increasing energy efficiency gained through the unification of transmission grids, reducing the cost and the environmental footprint of electricity. In this regard, the role of the TSOs is pivotal in direction to optimize the collaboration of their respective grids, with the aim of contributing to the creation of an integrated electricity system. On the other side, implementing the conditions for sharing resources of power generation can drive notable cost reductions and more limited uncertainty in infrastructure project investments.

When the reserves to ensure the reliability of power systems (which need to increase with a significant RES development) are mostly supplied by the conventional thermal generation of appropriate technology, reserve sharing between interconnected areas helps in reducing the overall necessity of conventional reserves [5,6]. It is common that power systems maintain reserves to keep reliability in case of a plant contingency or other abnormal variances in supply and demand. Reserve sharing among balancing areas indicates that each balancing area can keep a lower reserve capacity. These ancillary sharing services for neighboring TSOs mitigates the requirements of thermal generation support and the activation of any other balancing solution (like demand side management) while it is limited by interconnection capacity.

Possible scenarios for sharing reserves under high RES integration can promote a better utilization of current and future interconnections capacity. An interconnected power grid for a region represents a type of unified-infrastructure-a wide-area form of infrastructure that provides the basis for underlying power generation and cross-border energy trade to develop. Nevertheless, interconnecting power grids is not a simple process and requires cultural changes, the establishing of trust between countries and institutional reform over several decades, as well as clear and robust legislation/regulation. Furthermore, creating interconnected grids alone does not guarantee that they will drive the development of sustainable energy. They can provide a channel for either renewable or fossil-fueled electricity and only correct policy can ensure the achievement of the energy transition targets.

The EU sponsors projects of common interest (PCIs) for cross-border interconnectors where market integration is enhanced [7]. The current target for electricity interconnectivity [8] for each European Member State is that it should be equal to $10 \%$ by 2020 , rising to $15 \%$ by 2030 , the latter being established in the Regulation (EU) 2018/1999, assuming that each new interconnection project can be subject to a cost-benefit analysis and realized only if the potential benefits overcome the costs. The TSOs should cooperate at the regional level to control cross-border flows and harmonize capacity adequacy and system security assessments.

The remainder of this paper is structured as follows. Section 2 describes the European Mediterranean Integration: 2030 horizon and current status. Section 3 presents the energy scenarios that were examined. The survey of technologies and technical solutions for grid integration is located in Section 4. The following Sections 5 and 6 present the Island Paradigm and the new interconnection project Tunisia-Italy. The Discussion and Conclusions sections sum up the paper outputs and inferences as well as formulate the recommendations after the COVID-19 pandemic for TSOs.

\section{Euro Med Integration and Energy Transition: 2030 Energy Landscape vs. Today}

\subsection{Med-TSO Objective}

Med-TSO promotes the planning and implementation of an integrated energy market in the Mediterranean region. The objective can be realized through collaboration between members on network planning, specifically on new cross-border interconnections, as well as on system interoperability based on harmonization, transparency and non-discriminatory technical rules. Moreover, there are numerous Med-TSO activities regarding workshops, webinars and knowledge/experience sharing including those in the research and development sector. 
Initially, Med-TSO conducted the Master Plan of the Mediterranean electricity interconnections in 2013. Subsequently, Med-TSO developed the Mediterranean Project I from 2015 to 2018, envisaging a reference Euro-Med grid, defining the set of rules for a regional grid code and focusing on resource sharing for increasing cross-border energy exchanges. For the first time, Med-TSO and the European Network of TSOs of electricity (ENTSO-e) are depicted in a grid map (https://www.entsoe.eu/data/map/), as presented in Figure 1.

Moreover, Med-TSO has continued the activities of Project I to Project II from 2018 up today in order to strengthen the collaboration, both in system development planning as well as operation. Besides, Med-TSO has developed cooperation with the Mediterranean Regulators for Energy (MEDREG) as well as with the ENTSO-e and ENTSO-g organizations.

The current status of grid connectivity in the Mediterranean region shows three differentiated situations:

1. A sufficient endowment in interconnection within the North Shore countries but with a level of utilization that is not yet satisfactory.

2. Insufficient endowment in interconnection infrastructures within the South Shore countries, also with an insufficient utilization as well as synchronization difficulties.

3. A poor North-South interconnection, limited in volume and topology, with only two links at the western and eastern extremities of the ring (Spain-Morocco, Turkey-Syria).

\subsection{North-South Interconnections and Mediterranean Cooperation}

The EU considers that interconnections to third countries, for instance with the neighbors of the Mediterranean, have prospects towards regional energy transition, RES integration and security of supply, as well as being able to promote regional welfare, economic development, cooperation and sustainability. Currently, there are 10 interconnections between the EU and neighboring countries; among them only two in the southern and eastern Mediterranean border: Turkey and Morocco. Turkey's transmission grid is interconnected with South-East Europe's synchronous $400 \mathrm{kV}$ grid through one transmission line to Greece and two lines to Bulgaria for a total nominal capacity of $1.9 \mathrm{GW}$. Morocco's grid is linked with Spain through two $400 \mathrm{kV}$ subsea cable lines with a thermal capacity of $1.4 \mathrm{GW}$ and a Net Transfer Capacity of 900/600 MW from Spain to Morocco and vice versa. The Italy-Tunisia interconnection project is expected to be the next one and is currently under implementation.

The Union for the Mediterranean (UfM), which is a political collaboration between the EU and the Mediterranean countries, promotes economic integration across 15 neighbors to the EU's South in North Africa, the Middle East and the Balkans region. The following countries, Algeria, Egypt, Israel, Lebanon, Morocco and Tunisia, are direct neighbors to European countries. Collaboration in the energy and climate fields is of high importance of the Euro-Med partnership in order to address energy and climate change challenges in the Mediterranean area while proceeding towards more secure and sustainable energy models. 


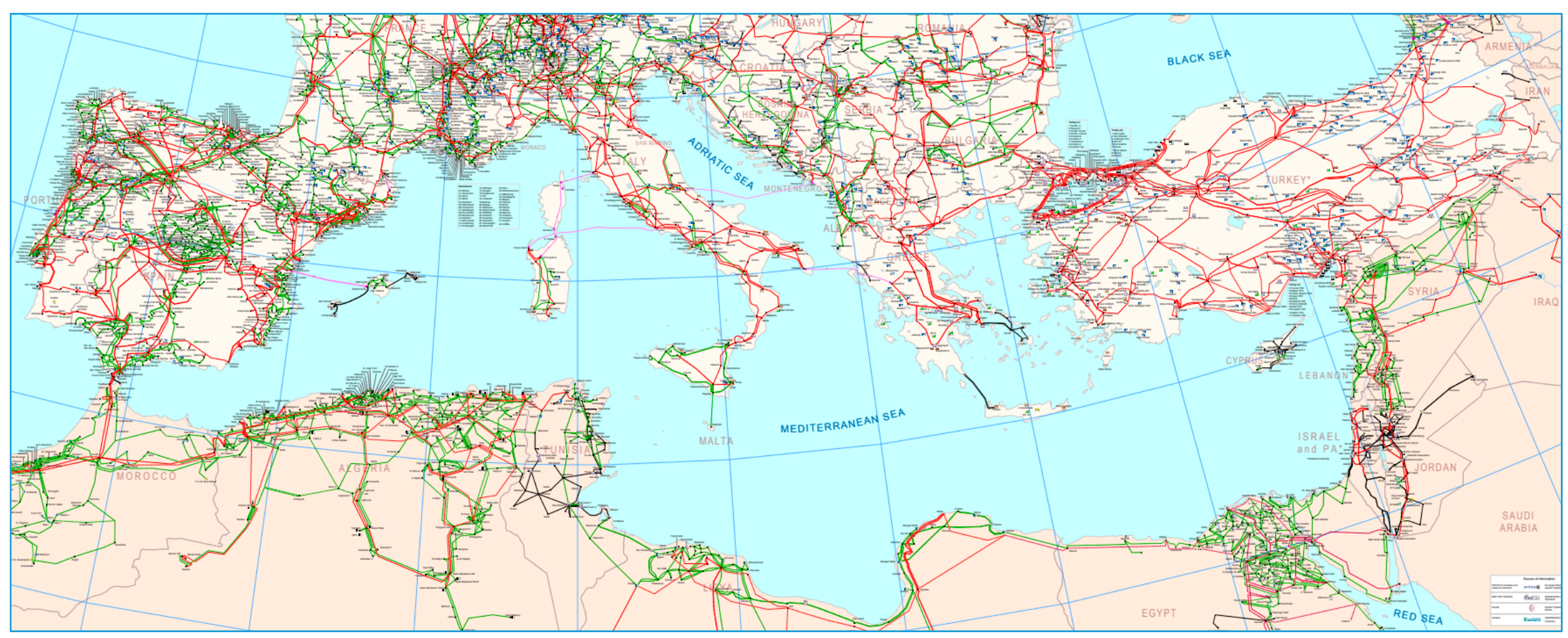

Figure 1. Joint ENTSO-e and Med-TSO map snapshot of the current transmission grids in the Mediterranean area [Source: ENTSO-e web-site]. 


\subsection{Euro-Mediterranean Power Grid Integration}

Taking into account this situation, Med-TSO [9] has developed many activities aimed at improving the Mediterranean Power Grid integration, fostering the cooperation between national TSOs in order to facilitate a coordinated common planning and development of interconnections, a common evaluation of electricity markets and various demand and supply characteristics, the harmonization of technical rules, the promotion and exchange of information and some convergence in sector operations.

In this framework, Med-TSO has developed the Master Plan 2030 (MP2030) of the wide Mediterranean Transmission Network: it is the expansion plan of the interconnections among the 20 power grids operated by the Transmission System Operators members of the Med-TSO Association. The plan is synchronized with the analogous ENTSO-E Ten Year Network Development Plan [10] and 2030 refers to its time horizon.

MP2030 studies the feasibility of 15 main cross-border projects between neighbor grids and the essential internal reinforcements projects to assure suitable security standards. It includes new corridors between the EU countries and their neighbors in the South. Figure 2 presents the typical topology of the interconnected national transmission systems in the Mediterranean area.

These projects focus on enhancing the cross-border connections, including those useful to integrate the EU energy market, so as to enable the integration of RES in the whole region, guarantee energy security within the region and promote the grid integration deployment both at the regional and Euro-Med level. The Master Plan is the output of a strong and deep collaboration among the Med-TSO Members and represents the most concrete expression of the Euro-Med cooperation for developing an integrated Mediterranean power grid and the related willingness to share knowledge and information.

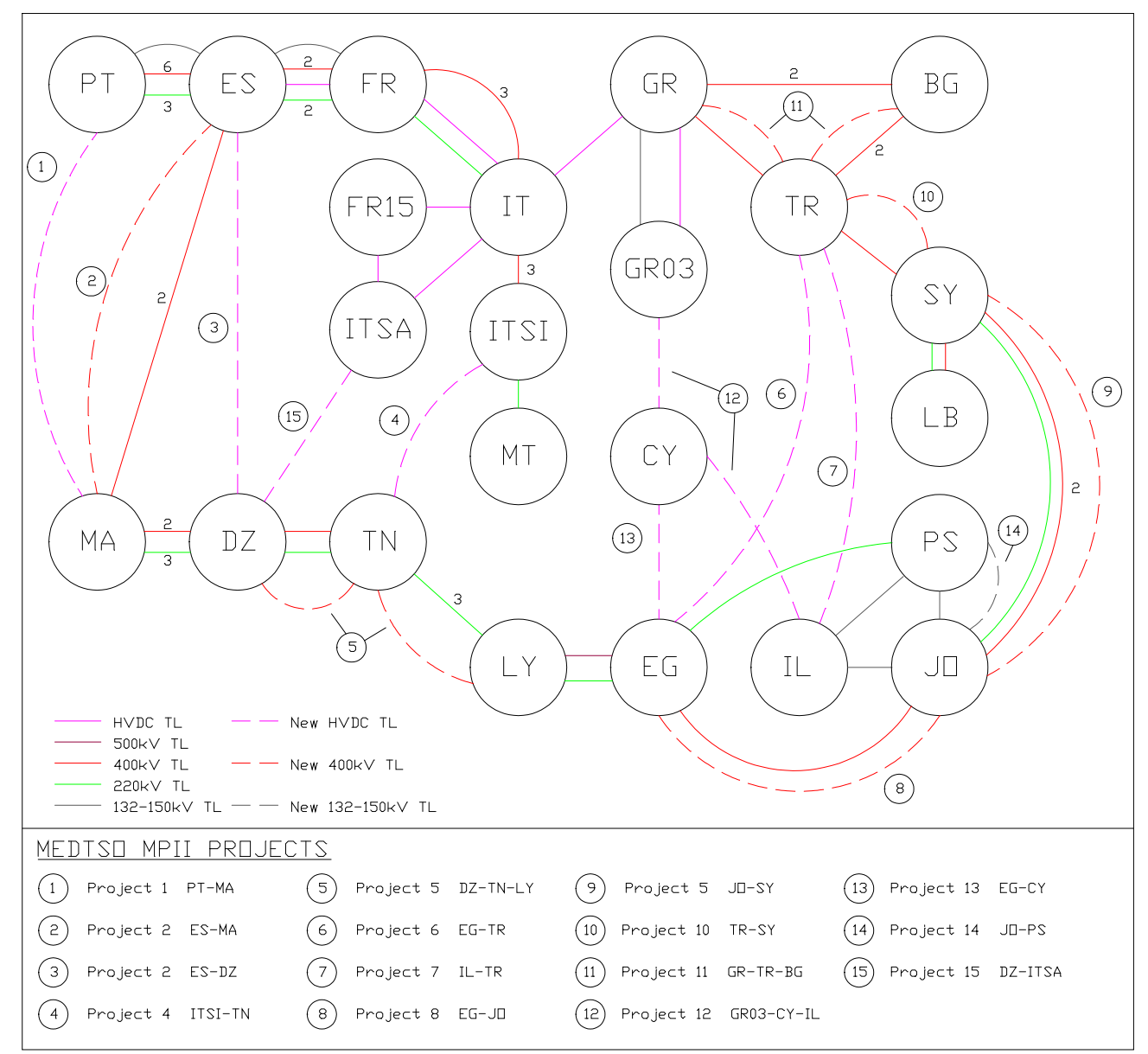

Figure 2. Typical topology of current/under-construction (continuous lines) and under-study (dotted lines) interconnections between Med-TSO members. 


\section{Mediterranean Energy Transition to 2030: Energy Scenarios}

As a foundation and development framework for its MP2030, Med-TSO has investigated the evolution of the energy landscape in the whole region to 2030, building and analyzing three Energy Scenarios, each driven by different but reasonable assumptions about electricity demand dynamics, climate change issues and established national policies [11-14]. The three scenarios are:

- Scenario 1-National development: based on a positive yet conservative option for long-term economic growth in the Mediterranean region. This trend is also accompanied by moderate population growth. The development of renewable energies corresponds to commitments already made and national energy policies. The improvement of energy efficiency presents a limited development while there is little transfer of uses towards electricity.

- Scenario 2-Green development: considers a Mediterranean region that benefits from a good development of macroeconomic trends. Emphasis is placed on the development of RES, especially with the construction of large production facilities, but also with the development of decentralized production and the growing role of prosumers. Efforts to improve energy efficiency focus on the residential sector and industry, resulting in the emergence of new uses of electricity.

- Scenario 3-Mediterranean evolution: is based on strong population growth, especially on the South and East coast, accompanied by a dynamic economy based on a strong development of industrial sectors and services. The ambitions for the development of RESs and the reduction in greenhouse gases (GHGs) are increased and can rely on regional cooperation and enhanced interconnection between countries. New uses of electricity are developing significantly, while at the same time efforts are being made to improve energy efficiency.

Each scenario depicts a different regional energy landscape in terms of the 2030 situation for the climate-relevant issues:

\section{Generation, RES Development and GHG Emission Reduction}

- Scenario 1 The development of renewable energies is moderately strong, corresponding to commitments already made and national energy policies. It relies, on the southern and eastern shores of the Mediterranean, on a high potential of massive RES deployment. Technological choices focus on the most profitable and mature solutions, as a consequence of the economic and weather conditions specific to each country. Gas fired power plants (GFPPs) continue to be important players in the energy mix in the Mediterranean, while storage is developing only slightly.

- Scenario 2 RES development is intensive but more decentralized with high penetration of small-scale PV driving GHG emission reduction, along with high generation from wind. In general, GFPPs make only a small contribution to adequacy, as well as to supporting the system in the early stage as coal is withdrawn. Storage units continue to be a key part of the system.

- Scenario 3 Renewable development is very high (with even more ambitious targets than the national ones). This growth is more centralized than in the "Green development" scenario. The really high increase in demand due to macro-economic trends (basically GDP and population) is also sustained on:

o Air-conditioning sustainable growth in Southern and Eastern banks related to residential sector increase.

o Electric vehicles development based on national policies and high fuel prices.

o Ambitious efficiency plan about household isolation or public lightning, etc.

o This scenarios are also characterized by the shift from gas and oil to electricity (basically due to heat pumps but also in the industrial sector). This shift is added to the electrification of the transport sector foreseen in the green development scenario. 
New Demand and Energy Efficiency

- Scenario 1 In a context of low economic and demographic growth, new uses in the residential and service sectors are growing moderately. At the same time, efforts to improve energy efficiency are moderate, penalized by the investment cost, including in industry. Progress in the decarbonisation of the transport sector is proceeding slowly, with a fleet of vehicles remaining largely moved by fossil fuels. Electric and hybrid vehicles are developing moderately, with customers favoring internal combustion vehicles above all for price reasons. National initiatives may, however, encourage electric vehicles, especially for economic or energy policy reasons.

- Scenario 2 There is significant deployment of heating of better energy efficiency (insulation of existing buildings and moderate increase in new buildings), which leads to a significant reduction in the total heat demand. On the other hand, the increase in energy efficiency in the residential and industrial sector, with the use of electric and gas heat pumps, hybrid solutions, more efficient boilers and micro CHP, contributes to the transformation of the demand sector and to an overall increase in the demand for electricity. Significant progress is noted in the decarbonisation of the transportation sector through the use of a variety of different technologies: electrification of private transport observes very high levels of growth with the introduction of electrical vehicles, but equally renewable liquid fuels, gas and hydrogen vehicles introduced in the public sector contribute greatly, especially for heavy goods trucks, shipping and aviation.

- Scenario 3 The really high increase in demand due to the macro-economic trends (basically GDP and population) is also sustained on:

o Air-conditioning sustainable growth in Southern and Eastern banks related to the residential sector increase.

o Electric vehicles development based on national policies and high fuel prices.

- Ambitious efficiency plan about household isolation or public lightning, etc.

o This scenarios are also characterized by the shift from gas and oil to electricity (basically due to heat pumps but also in the industrial sector). This shift is added to the electrification of the transport sector foreseen in the green development scenario.

Technology Development

- Scenario 1 The technologies remain fairly close to those currently used, as the economic context favors the use of mature and proven solutions. Most of the progress is driven by the scale effects induced by the development of renewable energies.

- Scenario 2 Decentralised energy sources are strongly developed with a greater number of prosumers engaged in decarbonisation and investing in low emissions energy technologies, driven by a propitious market mechanism. Further innovations in small scale generation and storage technologies are introduced, rendering energy generation that is more flexible with intermittent generation and allowing for the optimized management of the generation and consumption of electricity and heating.

- Scenario 3 Storage (including vehicle to the grid) and demand side response are critical parts of the system, in a centralized way, through big storage devices and through the figure of demand aggregators, respectively. Additionally, in European countries, power to gas will emerge as an opportunity for seasonal storage.

\section{Energy Demand}

Total energy demand in 2018 was $2 \mathrm{PWh}$ in the Mediterranean area. According to assumptions, the electricity demand is assumed to be increased by $24 \%$ ( $2.47 \mathrm{PWh})$ in Scenario 1, by $27 \%$ (2.53 PWh) in Scenario 2 and by 32\% (2.62 PWh) in Scenario 3. More specifically, it is noted that Syria and Lebanon will have over 100\% increase in demand. Moreover, Morocco, Turkey, Egypt, Algeria, Tunisia, 
and Jordan will meet increase over 50\% (up to 100\%). In addition, the following countries, Malta, Cyprus, Albania, Slovenia, and Greece, are predicted to have an increase in a range between $25 \%$ and $50 \%$. Furthermore, Spain, Israel, Italy, France, Portugal, Croatia, and Montenegro present lower rates of up to $25 \%$. Table 1 presents energy demand for 2018 and predictions for Scenario 1, 2 and 3.

In the Scenario 1, power production is going to be increased in 2030 by $18 \%$ in the conservative context, but by $14 \%$ (or $60 \mathrm{GW}$ ), thus being restricted, with an additional fossil fuel-based production infrastructure. In the Scenario 2, RES participation will be increased from the present $34 \%$ to $60 \%$ of the energy mix in the region and non-hydro renewable energy sources would expand to provide $66 \%$ of total installed capacity in the South by 2030, reaching 420 GW (53\% from solar PV). Finally, Scenario 3 is notably based on RES and energy efficiency but is always identified by a huge need of new projects on power generation and delivery assets. RES proportion over total installed generation capacity for Scenario 1,2 and 3 are presented at Table 2.

Table 1. Energy demand for 2018 and predictions for Scenario 1, 2 and 3.

\begin{tabular}{|c|c|c|c|c|c|c|c|c|}
\hline \multirow[b]{4}{*}{ Name } & \multirow[b]{4}{*}{ Code } & \multicolumn{7}{|c|}{ Energy Demand (excl. Pump Load \& Battery Charge) } \\
\hline & & \multirow{3}{*}{$\begin{array}{c}2018 \\
(\mathrm{TWh})\end{array}$} & \multicolumn{6}{|c|}{2030} \\
\hline & & & \multicolumn{2}{|c|}{ Scenario 1} & \multicolumn{2}{|c|}{ Scenario 2} & \multicolumn{2}{|c|}{ Scenario 3} \\
\hline & & & (TWh) & $\begin{array}{c}\text { Change } \\
(\%)\end{array}$ & (TWh) & $\begin{array}{c}\text { Change } \\
(\%)\end{array}$ & (TWh) & $\begin{array}{c}\text { Change } \\
(\%)\end{array}$ \\
\hline Italy & IT_ALL & 321.4 & 336.6 & $5 \%$ & 343.2 & $7 \%$ & 336.5 & $5 \%$ \\
\hline Greece & GR_ALL & 51.5 & 55.5 & $8 \%$ & 63.5 & $23 \%$ & 65.1 & $26 \%$ \\
\hline France & FR_ALL & 478.3 & 473.3 & $-1 \%$ & 473.3 & $-1 \%$ & 445.0 & $-7 \%$ \\
\hline Morocco & MA00 & 37.4 & 49.5 & $32 \%$ & 57.7 & $54 \%$ & 68.3 & $83 \%$ \\
\hline Algeria & DZ00 & 78.8 & 133.1 & $69 \%$ & 126.0 & $42 \%$ & 146.2 & $65 \%$ \\
\hline Tunisia & TN00 & 19.1 & 26.8 & $40 \%$ & 28.4 & $49 \%$ & 32.3 & $69 \%$ \\
\hline Libya & LY00 & 41.6 & 77.1 & $85 \%$ & 73.4 & $76 \%$ & 80.8 & $94 \%$ \\
\hline Egypt & EG00 & 196.7 & 309.2 & $57 \%$ & 289.3 & $47 \%$ & 329.2 & $67 \%$ \\
\hline Jordan & JO00 & 19.8 & 25.0 & $26 \%$ & 28.3 & $43 \%$ & 36.4 & $84 \%$ \\
\hline Palestine & PS00 & 6.5 & 10.0 & $54 \%$ & 10.7 & $65 \%$ & 11.5 & $77 \%$ \\
\hline Israel & IL00 & 60.4 & 64.5 & $7 \%$ & 79.1 & $31 \%$ & 86.2 & $43 \%$ \\
\hline Syria & SY00 & 19.0 & 35.6 & $87 \%$ & 45.8 & $141 \%$ & 57.3 & $202 \%$ \\
\hline Lebanon & LB00 & 15.1 & 23.9 & $59 \%$ & 29.9 & $98 \%$ & 29.9 & $98 \%$ \\
\hline Turkey & TR00 & 304.2 & 453.3 & $49 \%$ & 482.3 & $59 \%$ & 516.4 & $70 \%$ \\
\hline Cyprus & CY00 & 4.8 & 6.7 & $39 \%$ & 6.7 & $39 \%$ & 6.7 & $39 \%$ \\
\hline Slovenia & SI00 & 12.3 & 16.5 & $34 \%$ & 14.8 & $21 \%$ & 15.0 & $23 \%$ \\
\hline Croatia & HR00 & 17.3 & 17.5 & $1 \%$ & 19.0 & $10 \%$ & 19.3 & $12 \%$ \\
\hline Montenegro & ME00 & 3.7 & 4.4 & $20 \%$ & 3.2 & $-13 \%$ & 2.8 & $-24 \%$ \\
\hline Albania & AL00 & 7.2 & 9.9 & $39 \%$ & 9.9 & $39 \%$ & 9.9 & $39 \%$ \\
\hline Malta & MT00 & 2.0 & 3.0 & $49 \%$ & 3.0 & $49 \%$ & 3.0 & $49 \%$ \\
\hline Spain & ES00 & 240.7 & 279.0 & $16 \%$ & 284.8 & $18 \%$ & 278.8 & $16 \%$ \\
\hline Portugal & РТ00 & 50.9 & 57.6 & $13 \%$ & 53.4 & $5 \%$ & 42.5 & $-16 \%$ \\
\hline Total & & 1988.7 & 2468.0 & $24 \%$ & 2525.7 & $27 \%$ & 2619.1 & $32 \%$ \\
\hline
\end{tabular}


Table 2. RES proportion over total installed generation capacity for Scenario 1, 2 and 3.

\begin{tabular}{|c|c|c|c|}
\hline Country & Scenario 1 & Scenario 2 & Scenario 3 \\
\hline \multicolumn{4}{|c|}{ ENTSO-e Members } \\
\hline Italy & $69 \%$ & $69 \%$ & $65 \%$ \\
\hline Greece & $70 \%$ & $77 \%$ & $76 \%$ \\
\hline France & $62 \%$ & $63 \%$ & $59 \%$ \\
\hline Cyprus & $36 \%$ & $45 \%$ & $45 \%$ \\
\hline Slovenia & $67 \%$ & $40 \%$ & $39 \%$ \\
\hline Croatia & $87 \%$ & $48 \%$ & $48 \%$ \\
\hline Montenegro & $78 \%$ & $48 \%$ & $48 \%$ \\
\hline Albania & $93 \%$ & $48 \%$ & $48 \%$ \\
\hline Malta & $41 \%$ & $57 \%$ & $57 \%$ \\
\hline Spain & $77 \%$ & $78 \%$ & $76 \%$ \\
\hline Portugal & $89 \%$ & $89 \%$ & $88 \%$ \\
\hline Turkey* & $56 \%$ & $58 \%$ & $62 \%$ \\
\hline \multicolumn{4}{|c|}{ Non ENTSO-e Members } \\
\hline Morocco & $63 \%$ & $63 \%$ & $66 \%$ \\
\hline Algeria & $17 \%$ & $24 \%$ & $21 \%$ \\
\hline Tunisia & $37 \%$ & $42 \%$ & $42 \%$ \\
\hline Libya & $5 \%$ & $14 \%$ & $14 \%$ \\
\hline Egypt & $33 \%$ & $38 \%$ & $43 \%$ \\
\hline Jordan & $42 \%$ & $42 \%$ & $38 \%$ \\
\hline Palestine & $\mathrm{n} / \mathrm{a}$ & $\mathrm{n} / \mathrm{a}$ & $\mathrm{n} / \mathrm{a}$ \\
\hline Israel & $22 \%$ & $29 \%$ & $31 \%$ \\
\hline Syria & $29 \%$ & $33 \%$ & $35 \%$ \\
\hline Lebanon & $24 \%$ & $36 \%$ & $36 \%$ \\
\hline
\end{tabular}

\section{Survey of Technologies and Solutions to Fill the Gap and Reach the 2030 Target}

This Section highlights elements and innovations in terms of network development, operation procedures and regulatory landscape allowing the development of systems as part of sustainable development in the context of climate change.

These will include, inter alia:

- Adoption of solutions like HVDC and Storage.

- Technological solutions such as the Dynamic Line Rating and others.

- The integration of the Internet of Things "IoT" and artificial intelligence to optimize the control of interconnected systems in a single integrated network scheme to make the best use of inter-network complementarity.

- The establishment of automatic and real-time data collection and analysis systems for decision support for optimization of systems, especially with the integration of renewable energies in the context of sustainable development. Innovation in the field of the exploitation of the electrical system and the massive development of renewable energies has led to a revolution in the way of working in the control room, with, for example, almost real-time estimation and forecasting 
systems for wind and PV production, or the capacity to re-optimize intraday production and exchange programs.

- Proposed procedures and rules based on appropriate models of Trading Agreements (bilateral, multilateral) also independent from the market-level evolution.

\subsection{Interconnection Technology Options}

Cross-border transmission grid interconnections are of cornerstone importance in power systems development and will certainly play a critical role in the future. The related technologies can generally be divided into high voltage alternating current (HVAC) power technologies and high voltage direct current (HVDC) power technologies [15-23]. HVAC interconnection transmission lines or cables can interconnect synchronized AC networks, while HVDC links can be used for interconnection of asynchronous grids. HVDC technology has merits that make it an especially attractive choice for long-distance transmission, asynchronous interconnections, submarine cable crossings and offshore/onshore RES connection [24].

Generally, HVDC technology can increase the security, reliability and supply quality of interconnected systems and especially isolated grids, it ensures cost reduction and better use of energy production during peak load conditions, and it promotes energy export from one country to another by enabling participation in the electricity market. Converter station design is usually carried out with the aim to support the HV grid both in normal and emergency conditions by being able, in cases of black out, to take part in grid restarting and take part in frequency regulation.

Moreover, the benefits of HVDC can be economical, technical and environmental. In the aspect of economy of interconnected islands, it reduces constraints for the operation of the HVDC, increasing energy transfer between the mainland and islands, reducing the use of more expensive energy that had to be supplied by traditional thermal units in the islands.

In the aspect of technical benefits, it avoids the HVDC to operate with low short circuit currents, preventing damages to the converter stations and the neighboring transmission systems, it increases the availability of links, it facilitates planned outages and works in the transmission systems and it improves the decision making process, giving more information to the control center dispatchers. In the cases of environmental benefits, it contributes to the reduction in traditional thermal generation units that are connected in islands by contributing to the reduction in $\mathrm{CO}_{2}$ emissions.

HVDC links' typical arrangements may be symmetric monopole, asymmetric monopole (metallic or ground return) and bipole (metallic or ground return). There is also the case of back-to-back converter systems in order to couple two power grids. The HVDC technology can be improved as voltage source converters (VSC) or line-commutated converters (LLC) in the aspects of adaption of transmission of power limits, creating no reactive power issues by providing the possibility of generation and absorption, enabling black start possibility, as mentioned above, and working in weak AC grids with limited components; however, it has complex automation. Losses are low and it enables power flow reversal by reversing current almost instantaneously, with the appropriate XLPE (cross-linked polyethylene) cables, and generally is a new technology, having been around for the last 15 years.

Cable technologies vary between extruded cables, mass-impregnated cables, self-contained and fluid-filled cables. Technologies expand in the sense of constructing cables installed in deep sea depths. In leading cable technologies, qualification tests must be applied, such as bending, loading and polarity tests, long duration tests, external pressure with stand tests, tensile bending tests, etc. Stringent tests have to be applied every time an interconnection project is reaching deeper sea levels.

What is designed in the initial phase of HVDC has to be delivered; however, operational problems may appear that need to be taken into account in the new advances of such a technology. These may be resonance interactions between controls' and AC grids' harmonics, interactions between AC grid and HVDC controls, AC grids and exact behavior of controls, inherent and automatic management of the DC active power flow, combination of the AC flexibility and the DC controllability, and operation 
simplicity and fast capacity for response during and following severe disturbances in the AC system. This can be done by means of modifying the active power flow through the HVDC link according to power demand requirements of both ends, reducing the possibility of overloading in adjacent AC lines without the need to implement additional emergency controls, voltage control and reactive power capabilities.

Generally, when introducing these large scale HVDC projects, along with the technical engineering aspects of the technology, stakeholder management is the key, avoidance measures have to be designed at very early stages, each project is unique with different environmental sensitivities, and the definition of mitigation measures is difficult, since knowledge of marine environment is still lacking in many areas.

\subsection{Storage}

The high development of variable RES generation $[25,26]$ requires higher flexibility in the power grid operation, in order to respond to the variation and uncertainty of system operation at different hours [27]. Energy Storage is a promising technology to provide flexibility service to the system [28]. With the deployment of novel technology solutions, it is easy to plan and operate grid-centric storage. Dispersed storage systems are integrated to provide largescale rollout. One of the key roles for network operators is being neutral market enablers regarding storage grid services.

Storage can potentially improve the efficiency of the markets and utilize the RES integration by responding to its variability, on a long-term and short-term basis [29]. Any alternative technology that attaches such flexibility and optimized capacity could be investigated. With research and innovation advances, storage has characteristics to facilitate more efficient grid planning and operation in special conditions, for instance with load bottleneck, and may serve as an ancillary component to the transmission lines. Storage as part of the grid needs regulation to provide transparent services to the system without market influence.

So, advanced storage technologies provide:

- $\quad$ RES Integration in energy markets.

- Ancillary grid services.

- Enabling of optimal grid deployment, such us:

o Dynamic assets monitoring and operation in real-time limits;

o Dynamic grid configuration, such as phase shifters;

o Consumption and generation flexibility.

The storage can be complemented with demand response to optimize the related solutions, which can temporarily shift electricity production and consumption. The combination of energy storage and demand response provides efficient operation of thermal power plants at constant production output, curtailment avoidance of electricity generation, reduction in peak generating or transmission capacity, pricing stability, and emergency readiness.

From the TSO-side, energy storage can be a valuable asset and can provide various grid applications such as load management, power quality improvement, uninterruptable power supply, and increased efficiency and security of supply.

The current main technologies on energy storage are:

- Pumped-storage: Pumping technology is used to compensate the daily generating load, by transferring water to a high storage reservoir (lake), reclaiming the excess base-load capacity from RES or bulk sources. This water can be used for hydroelectric generation, usually as a high response to serve transient peaks in peak demand time frames. Pumped storage is currently the most cost-effective form of mass power storage and requires considerable capital expenditure (CAPEX). Pumped water systems are characterized by dispatchability and high efficiency in monitoring the variance of the load. 
- Electric batteries: Battery Energy Storage's main technology is based on rechargeable batteries (lead, lithium, nickel and sodium). The batteries' systems can be deployed at various sites of the power grid like bulk or RES generation, transmission and distribution substations, as well as at residential/industrial and public places.

- Power to Gas: The electric power to gas is the conversion of electricity to a gas fuel such as hydrogen and methane. Power to gas also brings the possibility of transferring energy from one system to another without the systems being interconnected [30]. For instance, the gas can be produced in one country and be transported to another country by ship (liquefied natural gas (LNG) carrier) where it is injected in the grid. This enables the transportation of green energy between countries that are not interconnected (or are poorly interconnected).

- Hydrogen: A hydrogen $\left(\mathrm{H}_{2}\right)$ fuel cell generates electricity via the hydrogen cycle which consists of the water electrolysis, the liquefaction or compression of the $\mathrm{H}_{2}$ and the conversion to electricity [31].

\subsection{Sectors Coupling}

Sectors coupling refers to combined technologies which focus on decarbonisation of the energy system. Electrification is without a doubt the most efficient and easiest way to decarbonize the European Economy, but some end-uses are hard to be decarbonised, at least not with the currently available technologies. Power to Gas (PtG) or/and Liquid (PtL) technologies should be used only where electrification is technically or economically not feasible. PtG is a good candidate to decarbonise heavy transports and non-energetic end-uses. Moreover, transportation of green fuels to autonomous/isolated systems, e.g., islands, or countries with low RES, via ships, is another application towards "virtual/no-physical" interconnections. These green energy commodities are an alternative option for grid integration. The role of power hubs development would be critical to electricity grids as well as to gas/liquid grids as an infrastructure that is characterised by optimal power switching/transition [32].

\subsection{Dynamic Thermal Rating (DTR)}

Today we are facing an increase in electricity demand and production, so conductors are often loaded up to the thermal limit. A TSO device reduces the power flow so as to maintain the loading of the transmission line up its rating [33]. The DTR of transmission lines may often release a useful increase in transfer capacity in comparison to the fixed static rating, and consequently the dynamic transmission capability allows TSO to facilitate transmission lines adaptively as well as safely with respect to marginal thermal temperatures. It is known that the transmission capacity is limited by the highest allowed current of the conductor, which is definitely not to be transcended in order to avoid excessive sags that could potentially violate the minimum allowed distances to the ground, vegetation, buildings, etc.

DTR requires precise knowledge of ambient weather conditions and conductor sag (tensioning technical design conditions) along the considered transmission line. The ampacity of the overhead line can be dynamically adapted to current or forecasted ambient conditions in order to increase the ampacity of the line. An increase in ampacity can be achieved from $15 \%$ up to $50 \%$ depending on the typical regional weather conditions. The higher rates can be achieved in regions where high wind generation has a strong transversal cooling effect on the line conductor.

Main advantages:

- Maximizing the exploitation of existing transmission lines depending on the weather and operational conditions.

- Improving the exploitation of RES generation, wind in particular.

- Reducing the need for new infrastructures, through an optimized utilization of the existing ones, with significant environmental benefits. 
DTR techniques are suitable for application on transmission lines located in areas where weather conditions cannot be predicted with any certainty and/or with strong ambient temperature and solar irradiance fluctuations across seasons [34,35].

\subsection{Smart Grids and Transmission Solutions}

Smart grids can be described as a new generation electricity network that integrates a wide area of technologies (sensors and measurement, informatics and communications, analytics and decision-making, automatic control) with electric power technologies and grid infrastructure. The main goal of smart grid and technology usage is to make the grid more flexible and reliable to face evolving challenging conditions, and in general to enable more efficient transmission [36-38] of electricity with increased integration of large-scale renewable energy systems. Smart technologies can include use of one or more of the following characteristics:

- High Transmission Capacity conductors and Dynamic Thermal Rating (DTR): maximizing existing lines' capacity depending on weather conditions.

- Synchronous Compensators (SC): increasing of the power system stability and security.

- Capacitors and Reactors: cost-effective management of reactive power and grid voltage profiles.

- Flexible AC Transmission System (FACTS) Technology.

- Grid scale Storage (GS): maximizing the use of non-programmable RES production and contributing to the power system regulation.

- $\quad$ Phase Shifting Transformers (PST): optimization of HVAC grid power flows.

- Smart management: improvement in the forecasting and management of distributed generation.

- The Reactive Power Management concept.

- High Voltage Direct Current (HVDC) technology.

- Synchrophasor technology, etc.

Specifically, smartening a power grid means that the new electricity network is finally characterized by observability, controllability, timely analysis and decision making, self-adapting and self-healing, and maximization of RES integration [39].

\subsection{Network Automation}

The integration of a growing amount of intermittent/variable renewable production leads to a more sensitive grid with rapid and unpredictable variations, thus making it necessary to set up data collection systems (sensors) in near real time and build automated procedures for their process and management [40].

Network-operating services, such as network automation and the use of client asset flexibility, will have a strategic role and will be a viable alternative to excess capacity investments.

More automated analysis will be integrated jointly with decision support at the local level to exploit the potential for flexible demand from electric vehicles, heat pumps, air-conditioning systems and certain processes in order to balance changes in demand and renewable energy production while reducing losses.

Capacity problems due to the intermittency of solar or wind power generation or the demand for electric vehicles will likely appear in many parts of the network simultaneously, and their solution will require non-manual decision-making procedures.

The operational decisions and related solutions can concern:

- Network automation including tap changers and smart transformers for the management of voltage levels in the network.

- Reconfiguring loops to reduce network losses to mitigate the effects of potential failures and the effects of faults themselves. 
- The automated use of demand-response procedures and local storage activation, which will help network managers reduce load peaks, thus reducing network capacity losses and problems.

\subsection{Data Management and Data Analytics}

The management of maintenance teams will be optimized, using more data and analytical intelligence. Network and plant maintenance is increasingly planned and executed based on the results and analysis of operational and other data (such as market data). With the development and deployment of sensors in the "Internet of Things (IoT)" electrical system, important data is available. To interpret and link them with other data from many different sources and locations, in order to draw conclusions and translate them into appropriate "actions", models are inevitable [41].

These are state and low load estimation models for power transmission and distribution systems, but other models will also be used depending on the applications. Network operators use models linking meteorological data, demand data, grid frequency and other sources to predict potential imbalances, intraday market prices and optimize their production and portfolio loads accordingly [42-44].

Since the substations are considered as the heart of the power grid, in the future, more attention will be given to the digitalization of substations, which will enable the collection of valuable data from the entire power grid. Digital substation operation is managed between distributed smart measurement devices interconnected by communications networks and can facilitate major benefits in terms of design and engineering, installation, and operation.

With the increasing use of advanced sensor and measurement systems in power systems, the availability of big-data sets presents a unique opportunity for improving system operation and planning in the context of the large-scale integration of intermittent energy sources. The pervasive RES integration, variable loads and cross-border interconnectors have led to to a key increase in operational uncertainty and variation. The development of accurate statistical and computational models is a basis for discovering the uncertainty of, and enhancing, real-time decision-making tools. Consequently, it becomes crucial to develop big data computing environments to handle such complex measurement sets with the challenges of volume, velocity, variety, and veracity $(4 \mathrm{Vs})$ for further investigation of the real-world problems in power systems.

Specifically, volume refers to the unprecedented massive amounts of data and involves challenges in data storage, data loading, and information analysis. For real-time tasks (e.g., outage prevention and efficient condition-based asset management), it is imperative to efficiently collect and process the data with sufficiently fast speed. In addition, different types of data sources such as social graphs, weather forecasting systems, and the web, result in the challenge of variety that require utilities to take into account the diversified information when solving planning, operation, and decision-making problems. Finally, veracity signifies the uncertainty of the data, including the accuracy and the quality of measured data.

Under this new reality, data analytics are facing significant challenges when employing conventional data analysis techniques in the applications of power systems. For the TSOs, it becomes necessary and difficult to deal with such amounts of variables and to predict stochastic outputs of wind and solar production. Concurrently, the TSO needs to ensure that the large generation over/under-supply that could occur due to this intermittency is considered and the system is kept well within the security boundaries. As a result, the increasing uncertainties affecting the system operating conditions drive the need for more effective real-time stability analysis tools. Heretofore, this has mainly involved running dynamic/stability analysis studies (e.g., simulating line outages) for a set of critical contingencies close to real-time to ensure that no operational constraint is violated. Nevertheless, there is a limit as to the number of simulations that can be conducted in real-time, seriously limiting the analysis scope and forcing TSOs to operate in a conservative and preventive manner, potentially foregoing actions that could lead to a safe yet more optimal use of the available energy resources. 
Transmission network expansion planning is facing the challenge of considering the system operational variability and uncertainty introduced by the increasing integration of RES. The ever-expanding spectrum of possible operating points entails the consideration of numerous scenarios within a cost-benefit analysis, which leads to computational complexity, especially when it comes to a long-term plans with high intermittent generation penetration. Each scenario of demand-generation patterns with a certain probability is used to solve the planning problem. Therefore, it is imperative to reduce the amount of operational states by selecting the representative scenarios from the original dataset. Modern scenarios configuration for the transmission expansion problem is crucial to generate an accurate solution in terms of operation and investment costs with a remarkably reduced number of operation states.

\subsection{Balancing Inter TSOs Platforms}

The balancing Inter TSO's (BALIT), hitherto applied among Portugal and Spain via the interconnections, is a successful case of a mechanism that may be adopted in other neighboring countries. BALIT provides transborder exchanges of balancing services and supports the trading of unused balancing services in a coordinated region. The platform can be applied to non-market-oriented countries and should be investigated so as to transform the market-related platform features with appropriate agreements between TSOs covering the technical and financial aspects [45].

\subsection{Multilateral Trading Arrangements}

With increasing shares of variable renewable energy in the Mediterranean basin, multilateral power trade can benefit all of the neighboring countries in terms of both increased system security and economic efficiency due to resource sharing [46]. A secure and economical power systems integration needs inter-jurisdictional collaboration across a wide range of sectors. Particularly, collaboration is needed in the inter-linked areas of long-term planning, system operations, energy exchanges or power trading and governance. System operations and power trade require the utilization of infrastructure built under long-term plans and the utilization of the infrastructure require some form of enabling governance framework to function properly [47].

\section{The Island Paradigm: Case Study and Lessons Learned}

In the process of grid integration towards climate change, the first thing that comes to mind is the massive RES integration in the system. The most ambitious goals of $100 \%$ renewable generation sometimes miss the technical hurdles of such ambition in light of the current technologies. Issues of system constraints, such as downward regulation, ramp rates and incorrect generation predictions of an electricity power system need to be addressed in a large scale of technological and institutional optical angles.

Let us take the analysis of a small isolated self-contained system as an example to understand the difficulties arising in the bigger picture. One of the biggest islands situated in the eastern Mediterranean area, has $1480 \mathrm{MW}$ thermal installed capacity (mainly with units of 220 and $130 \mathrm{MW}$ ), $180 \mathrm{MW}$ installed wind capacity and $150 \mathrm{MW}$ installed photovoltaic capacity, with its peak summer demand reaching $1075 \mathrm{MW}$ during summer. This situation is ideal, since the $150 \mathrm{MW}$ installed capacity of the photovoltaic generation contributes to the maximum demand during summer and it can be said that, with photovoltaics, the construction of a thermal unit is avoided.

On the other hand, wind generation contributes to $4.3 \%$ of total annual demand, more or less half of the RES penetration towards the targets set from EU. However, the drawbacks on the stability of such an isolated system are much more intense than interconnected systems, leading to issues such as:

- Downward regulation: During April, morning hours load demand reaches its minimum, at around $300 \mathrm{MW}$, having base units of 220 and $130 \mathrm{MW}$ struggling with their minimum operation, especially when the $185 \mathrm{MW}$ of wind generation pushes energy into the system at these 
hours. In order to keep the stability of the system in the cases where the wind generation is away from the predicted values, this energy is curtailed. With an international interconnection this low (or even negative), price energy could feed other systems.

- Ramp rate: The system cannot absorb sudden increases in wind generation since thermal generating units ramp rate cannot reduce as such. On the other hand, renewable generators consider wind generation spikes' alleviation as a reduction in the price of their investment. With international interconnections, these generation spikes can reach to other systems; however, care must be taken so that converter stations of HVDC interconnections can be adjusted to manage these spikes.

- Photovoltaic prediction variances: The large scale of photovoltaic in a system, especially when this applies as dispersed generation, creates the necessity of accurate weather predictions. The problem does not appear in summer where there is an abundance of sun. It appears during winter, late autumn and early spring months. Advanced dispersed profile readings are needed so as to compare them with weather conditions on various areas of photovoltaic units.

On the other hand, the more RES is injected into the system, the less the dispatched thermal generation has to be. In small and isolated systems, the fear of frequency and voltage distortion is bigger. Taking into account the above-mentioned problems in a small and isolated system, we can extrapolate to a bigger context of interconnected systems and how these can be faced in a technological, operational and institutional manner. This means that a problem we need to set up in an institutional manner is agreements between TSOs on the set-up of the co-ordination of downward regulation, wholescale photovoltaic generation prediction of inter country areas, as well as co-ordination of the operational parameter settings of HVDC inverter stations or AC systems' inertia when two or more TSOs plan interconnections between them.

Based on the above, when setting the objectives of improvement to meet the 2030 challenges for climate change and energy security, the following should be considered inter alia:

- To develop large scale pan-European or pan-Mediterranean software systems for the photovoltaic, wind and other RES generation forecast but also generation records. TSOs should have total live access to the RES forecasts and actual generation of other countries (not only their neighboring country) so as to be able to plan dispatched units that can provide sufficient reserves of downward capabilities in order to allow more the maximum RES penetration.

- To develop institutional agreements and co-operation of large scale pan-European or pan-Mediterranean network planning so that TSOs can set up consistent methods on how set operational specifications on international interconnections projects and national system reinforcement network development projects (Overhead lines, Underground cables or other equipment) that are needed as a result of international interconnection planning.

\section{Case Study-TUNISIA-ITALY Interconnection "ELMED Project"}

The project is promoted by the Terna, the Italian TSO, and STEG, the Tunisian Company of Electricity \& Gas, and it is also known as "ELMED" between Sicily (IT) and the Tunisia node (TU), as well as TUNITA project. The project is registered in the fourth list of PCIs encoded " 3.27 ". It is under implementation and its commissioning is expected by 2027 [48]. Figure 3 presents the ELMED interconnector.

The infrastructure project will create a link between the European and Northern African energy markets able to guarantee the security, stability and competitiveness of the energy supply, by ensuring a net transfer capacity (NTC) value of $600 \mathrm{MW}$. 


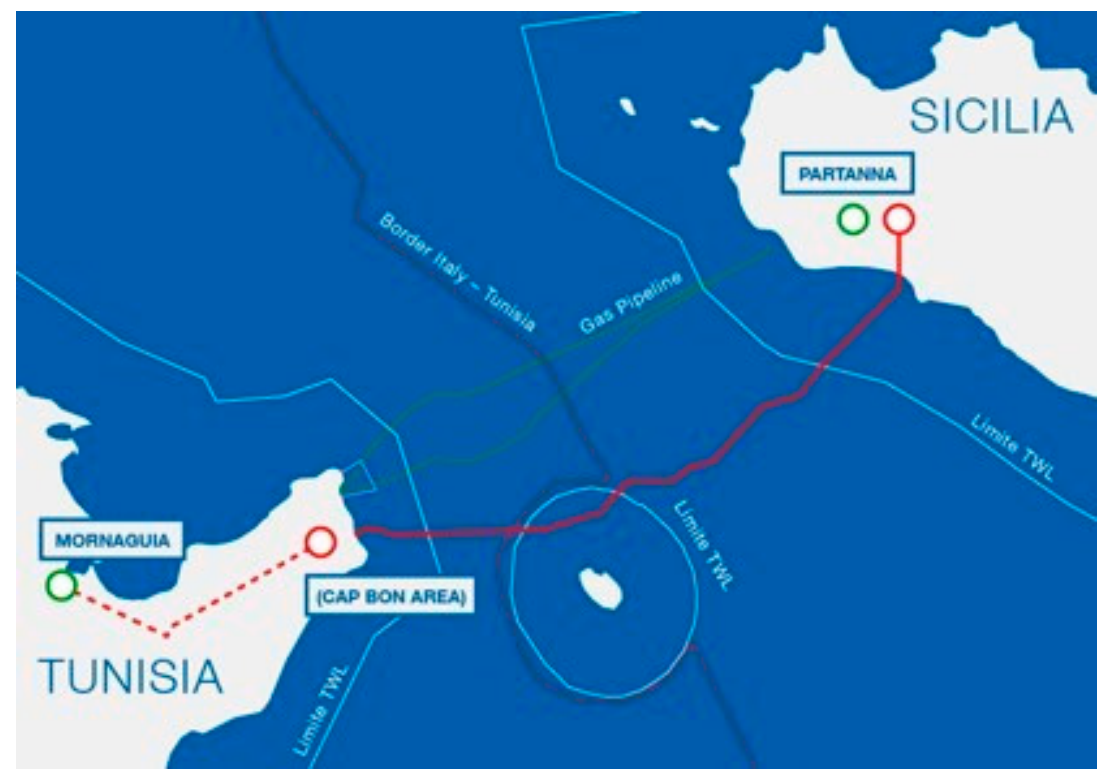

Figure 3. The ELMED project is the new interconnection between Partanna, Sicily (IT), and Menzel Temime, Tunisia (TU). [Source: TERNA SpA website].

The project consists of the realization of an undersea HVDC connection between the existing electrical substation in Partanna, TP, Italy, and a new built substation in Menzel Temime, Mlaaba, Cap Bon Peninsula, Tunisia.

More specifically, the interconnection will be moulded by the following main parts:

- Two alternating/direct current (AC/DC) converter Stations.

- Terrestrial and marine Cable: n.1 marine single-pole cable between the two landing points in Tunisia and Italy; n.1 underground single-pole cable from each landing point (where it is jointed with the marine cable) to the relevant converter substation; $n$. 1 electrode line between each landing point and the relevant converter substation; $n$. 2 marine electrode cables between each landing point and one electrode to be located at the sea-side.

- The project will contribute to reaching the core objectives laid down in the Trans-European Networks-Energy (TEN-E) Regulation and the European Green Deal key policy areas, including the New Strategy for Africa.

- The electrical interconnection between the two shores of the Mediterranean can bring significant benefits to the entire European electricity system, especially in terms of technological innovation, balancing, solidarity and security of supply, by providing higher efficiency and lower electrical losses, as well as increasing RES integration.

In detail:

- It will realize a bridge between Europe and North Africa of major importance under the objective of a Euro-Mediterranean interconnected system, to achieve markets' integration, to reduce balancing problems, to improve the security of supply and sustainability;

- It will strengthen the European electricity market by enabling power exchanges which are very helpful to balance RES generation in Southern Europe, to prevent RES curtailment and improve stability and security of the system, thus helping Italy to achieve the European targets;

- The reinforcement in the transmission system will overcome current constraints on operational flexibility and possible constraints in the management of the overall system;

- It will allow the reduction in $\mathrm{CO}_{2}$ emissions and the establishment of a sustainable development path in the energy sector, with possible positive spillovers in other industry segments;

- It will contribute to decreasing barriers to the electricity exchanges in the north of Italy; 
- In terms of solidarity, with the realisation of the project, Sicily, as an economically depressed region, could be favorably affected by the RES transition in order to overcome economic constraints;

- The EU supports and encourages the developing of the energy sector, including cross-border interconnections between EU and Tunisia and recognises the potential of the project for improving closer links between the EU and North-African regions.

As recognition of the benefits achieved through the above-mentioned objectives, the project has received endorsements by the European Parliament and Commission, besides the Governments of Malta, France, Germany and Algeria. The Governments of Italy and Tunisia signed, on 30 April 2019, an Inter-Governmental Agreement, which strongly supports the realization of the interconnection, as it recognizes its strategic value for both countries and for the whole Mediterranean basin. The Tunisia-Italy interconnection project is included in the Italian Plan for Energy and Environment (PNIEC), as it is considered as a key element towards a sustainable energy framework.

\section{Discussion}

The paper presents grid integration aspects towards energy transition of the Mediterranean area. The national transmission systems are the fundamental infrastructures that can enable the distributed RES penetration and the reduction in $\mathrm{CO}_{2}$ emissions. The role of the cross-border interconnections is critical to meet the targets set by EU and adopted widely by member states as well as by non-member states in a framework of climate change-sensitive national strategies for energy and the climate.

The roadmap to 2030 consists mainly of new international transmission interconnectors between neighbor countries and beyond. It is made clear that the interconnections are beneficial for the countries. The Technical Committee 1 (TC1) of Med-TSO studies 15 cross border interconnection projects that mainly interconnect the South Europe countries to North Africa as well as Middle Eastern countries. These electricity corridors deploy a Master Plan of network development around the Mediterranean. The economic scenarios studies estimate that up to 2030 there will be an increase in RES generation capacity and a decrease in conventional thermal power generation. The framework of climate change and the energy transition promotes the planning of new interconnectors between the countries, the deployment of electricity markets and energy exchanges, and the removal of energy isolation.

Emerging technologies of electric power transmission and distribution can support the energy transition. Storage by means of hydro pumping, batteries and power to gas, promises outstanding flexibility together with demand side response management systems. Digitalization of energy with smart meters, network measurement, control and automation equipment and software are critical infrastructures. Moreover, data management and data analytics are useful tools for TSOs, DNOs and energy providers/traders in order to develop intelligent operations/business processes and services. TSO-DNO cooperation [49] will optimize the planning, operation and maintenance of transmission and distribution networks and improve performance indicators. Moreover, the cooperation of TSOs [50] beyond the projects of common interest such as the development of balancing inter TSO platforms, regional security coordination centers, multilateral trading agreements are the drivers to outbound grid integration.

The common vision of the TSOs, which participate at Med-TSO, is the actions needed to plan and develop a sustainable grid infrastructure linking the energy markets in the framework of the climate change and the energy transition.

\section{Conclusions}

Grid integration is of paramount importance in interconnected power systems on the roadmap towards energy transition in order to meet the climate targets. Among new cross border interconnection corridors of common interest, new technologies and solutions can be beneficial and enable strengths and opportunities. Med-TSO promotes strong multilateral cooperation between TSO members as a strategy of regional development and as a technical platform that can release the evolution and integration of Mediterranean power grids, fostering security and socio-economic sustainable growth in 
the region. Most of new interconnection projects can spread numerous merits in wide areas. Specifically, there are positive consequences in the market by reducing and harmonizing price differences, as well as in the adequacy and security of supply, and in system operation optimization with improved flexibility and stability ancillary services. Moreover, multi-layered interactive TSO-DNO cooperation is necessary for an Internet-like [51], decentralized, efficient, resilient and interactive grid with advanced digital automation, protection and control operations, which would improve the end-to-end quality of energy services and consumers' experience, from generation to consumption edges. The evolved smart grid infrastructure with wide storage capacity can mitigate RES curtailment, and minimize and share thermal production. Moreover, new fields of electrification, e.g., transportation (Vehicle-to-Grid, shipping electrification/electric ports), heat pumps etc., as well as sectors' coupling (Power-to-Gas/Liquid), are promising technologies for a sustainable power system.

During the COVID-19 pandemic, the Mediterranean TSOs responded to their responsibilities and focused their efforts on operating a secure and sufficient supply of electricity for critical infrastructures and facilities. The TSOs' task in the consequence of this unprecedented crisis is to ensure that, when the Mediterranean region's economy and society recover after the pandemic recession [52], they do so in a responsible way, contributing to green recovery and achieving a climate-neutral development. To succeed in the sustainable post-pandemic speedup, Med-TSO recognizes the key role of TSOs in system integration, towards a unified grid of interconnected systems built on four cornerstones [53]:

- Multi-sectoral grid planning [54,55] and forward-looking investments.

- Adoption of pervasive electrification by States' decarbonisation policies, as electricity is the supreme option for clean energy.

- Investment in research and innovation in low-carbon, purpose-built infrastructure and in a "cyber-physical" power supply system.

- Straightforward recovery of the whole electricity value chain and market.

The emerging challenges motivate Med-TSO to continue and strengthen the cooperation activities by implementing the upcoming "TEASIMED" project, towards an efficient, adequate, sustainable and interconnected Mediterranean power system.

Author Contributions: Conceptualization A.M., C.P.; writing—editing, C.P., A.M., G.C.; resources, A.M., E.B.; review, E.B., M.G.F. All authors have read and agreed to the published version of the manuscript.

Funding: This research was funded by EC DG NEAR, grant number ENI/2018/397-494 “Med-TSO—Mediterranean Project II".

Acknowledgments: The authors express their acknowledgements to the members of Planning Technical Committee (TC1) of Med-TSO for their comments on the study.

Conflicts of Interest: The authors declare no conflict of interest.

Disclaimer: The views, opinions and assumptions expressed in this article are those of the authors, for scientific and research purposes, and do not necessarily reflect the official policy or position of Med-TSO and the TSOs, or other Organizations and Institutions.

\section{References}

1. United Nations. Transforming our World: The 2030 Agenda for Sustainable Development (A/RES/70/1); United Nations: New York, NY, USA, 2015.

2. United Nations. Paris Agreement; United Nations: New York, NY, USA, 2015.

3. IRENA. Global Energy Transformation: A Roadmap to 2050 (2019 Edition); IRENA: Abu Dhabi, UAE, 2019.

4. IRENA. Climate Change and Renewable Energy; IRENA: Abu Dhabi, UAE, 2019.

5. Wang, H.; Di Pietro, G.; Wu, X.; Lahdelma, R.; Verda, V.; Haavisto, I. Renewable and Sustainable Energy Transitions for Countries with Different Climates and Renewable Energy Sources Potentials. Energies 2018, 11, 3523. [CrossRef]

6. Sun, D.; Olmos, L.; Rivier, M. Considering Local Air Pollution in the Benefit Assessment and Cost Allocation of Cross Border Transmission Projects. Energies 2020, 13, 1426. [CrossRef] 
7. European Union. Commission Delegated Regulation (EU) 2020/389 of 31 October 2019 Amending Regulation (EU) No 347/2013 of the European Parliament and of the Council as Regards the Union List of Projects of Common Interest; European Union: Brussels, Belgium, 2020.

8. European Union. Towards a Sustainable and Integrated Europe, Report of the Commission Expert Group on Electricity Interconnection Targets; European Union: Brussels, Belgium, 2017.

9. Med-TSO, Mediterranean Project 2. Available online: https://www.med-tso.com/ (accessed on 1 July 2020).

10. ENTSO-e, Ten-Year Network Development Plan. Available online: https://tyndp.entsoe.eu/ (accessed on 1 July 2020).

11. European Commission. Communication: A Policy Framework for Climate and Energy in the Period from 2020 to 2030 ; EC: Brussels, Belgium, 2014.

12. European Commission. 2030 Climate and Energy Goals for a Competitive, Secure and Low-Carbon EU Economy; EC: Brussels, Belgium, 2014.

13. European Commission. Green Paper: A 2030 Climate E Energy Framework; EC: Brussells, Belgium, 2013.

14. European Commission. 2030 Climate and Energy Framework—Reaction to Claims About the Commission's Economic Analysis; EC: Brussels, Belgium, 2014.

15. HVDC planning, technology selection and specification. Cigre Tutorial TTR007 2018.

16. Nanou, S.I.; Papathanassiou, S.A. Grid Code Compatibility of VSC-HVDC Connected Offshore Wind Turbines Employing Power Synchronization Control. IEEE Trans. Power Syst. 2016, 31, 5042-5050. [CrossRef]

17. Designing HVDC grids for optimal reliability and availability performance. Cigre TB713 2017.

18. Technical requirements and specifications of state-of-the-art HVDC switching equipment. Cigre TB683 2017.

19. Guide for the Development of Models for HVDC Converters in a HVDC Grid. Cigre TB604 2014.

20. Recommended voltages for HVDC grids. Cigre TB684 2017.

21. Ardelean, M.; Minnebo, P. HVDC Submarine Power Cables in the World: State-of-the-Art Knowledge. JRC Rep. 2015.

22. L'Abbate, A.; Careri, F.; Calisti, R.; Rossi, S.; Fulli, G. Long-term HVDC developments in the European power system: The Baltic case in GridTech analysis. In Proceedings of the 5th International Conference on Power Engineering, Energy and Electrical Drives (Powereng), Riga, Latvia, 11-13 May 2015; pp. 283-290.

23. Kaushal, A.; Van Hertem, D.; Hertem, D. An overview of Ancillary Services and HVDC systems in European Context. Energies 2019, 12, 3481. [CrossRef]

24. Murray, B. The Development of cross border interconnection and trading. Glob. Energy Interconnect. 2019, 2, 254-263.

25. Rakhshani, E.; Rouzbehi, K.; Sánchez, A.; Tobar, A.C.; Pouresmaeil, E. Integration of Large Scale PV-Based Generation into Power Systems: A Survey. Energies 2019, 12, 1425. [CrossRef]

26. Kumar, G.V.B.; Sarojini, R.K.; Palanisamy, K.; Padmanaban, S.; Holm-Nielsen, J.B.; Padmanaban, S. Large Scale Renewable Energy Integration: Issues and Solutions. Energies 2019, 12, 1996. [CrossRef]

27. Gough, M.; Santos, S.F.; Javadi, M.S.; Castro, R.; Catalão, J.P. Prosumer Flexibility: A Comprehensive State-of-the-Art Review and Scientometric Analysis. Energies 2020, 13, 2710. [CrossRef]

28. Holm-Nielsen, J.B.; Faruque, H.M.R.; Sunny, S.H.; Mohammad, N.; Nawar, N. A Comprehensive Review on Energy Storage Systems: Types, Comparison, Current Scenario, Applications, Barriers, and Potential Solutions, Policies, and Future Prospects. Energies 2020, 13, 3651. [CrossRef]

29. Rancilio, G.; Lucas, A.; Kotsakis, E.; Fulli, G.; Merlo, M.; Delfanti, M.; Masera, M. Modeling a Large-Scale Battery Energy Storage System for Power Grid Application Analysis. Energies 2019, 12, 3312. [CrossRef]

30. Walker, S.; Al-Zakwani, S.; Maroufmashat, A.; Fowler, M.; Elkamel, A. Multi-Criteria Examination of Power-to-Gas Pathways under Stochastic Preferences. Energies 2020, 13, 3151. [CrossRef]

31. Dolci, F.; Thomas, D.; Hilliard, S.; Guerra, C.F.; Hancke, R.; Ito, H.; Jegoux, M.; Kreeft, G.; Leaver, J.; Newborough, M.; et al. Incentives and legal barriers for power-to-hydrogen pathways: An international snapshot. Int. J. Hydrog. Energy 2019, 44, 11394-11401. [CrossRef]

32. Vandenbergh, P.; Giaccaria, S.; Gerbelova, H.; Purvins, A.; Costescu, A.; Bolado Lavin, R. Coupling power and gas systems models. JRC 2019.

33. Heckenbergerová, J.; Hosek, J.; Hosek, J. Dynamic thermal rating of power transmission lines related to wind energy integration. In Proceedings of the 2012 11th International Conference on Environment and Electrical Engineering, Venice, Italy, 18-25 May 2012; pp. 798-801. [CrossRef] 
34. Maksic, M.; Kosec, G.; Djurica, V.; Souvent, A.; Trobec, R. Dynamic thermal rating of power lines in raining conditions-Model and measurements. In Proceedings of the 2016 IEEE Power and Energy Society General Meeting (PESGM), Boston, MA, USA, 17-21 July 2016; pp. 1-4.

35. Teh, J.; Lai, C.-M.; Muhamad, N.A.; Ooi, C.A.; Cheng, Y.-H.; Zainuri, M.A.A.M.; Ishak, M.K. Prospects of Using the Dynamic Thermal Rating System for Reliable Electrical Networks: A Review. IEEE Access 2018, 6, 26765-26778. [CrossRef]

36. Ćalasan, M.P.; Konjić, T.; Kecojević, K.; Nikitović, L. Optimal Allocation of Static Var Compensators in Electric Power Systems. Energies 2020, 13, 3219. [CrossRef]

37. Bruno, S.; De Carne, G.; La Scala, M. Distributed FACTS for Power System Transient Stability Control. Energies 2020, 13, 2901. [CrossRef]

38. Kotsampopoulos, P.; Georgilakis, P.S.; Lagos, D.T.; Kleftakis, V.; Hatziargyriou, N.D. FACTS Providing Grid Services: Applications and Testing. Energies 2019, 12, 2554. [CrossRef]

39. ITU. Focus Group on Smart Grid "Smart Grid Overview", Deliverable Smart-O-34 Rev.4; ITU: Geneva, Switzerland, 2011.

40. Della Giustina, D.; De Sotomayor, A.A.; Dedè, A.; Ramos, F. A Model-Based Design of Distributed Automation Systems for the Smart Grid: Implementation and Validation. Energies 2020, 13, 3560. [CrossRef]

41. Nastasi, B.; Manfren, M.; Noussan, M. Open Data and Energy Analytics. Energies 2020, 13, 2334. [CrossRef]

42. Saldaña-González, A.E.; Sumper, A.; Aragues-Penalba, M.; Smolnikar, M. Advanced Distribution Measurement Technologies and Data Applications for Smart Grids: A Review. Energies 2020, 13, 3730. [CrossRef]

43. Jiang, Z.; Shi, D.; Guo, X.; Xu, G.; Yu, L.; Jing, C. Robust Smart Meter Data Analytics Using Smoothed ALS and Dynamic Time Warping. Energies 2018, 11, 1401. [CrossRef]

44. Lucas, A.; Jansen, L.; Andreadou, N.; Kotsakis, E.; Masera, M. Load Flexibility Forecast for DR Using Non-Intrusive Load Monitoring in the Residential Sector. Energies 2019, 12, 2725. [CrossRef]

45. Deliverable 3.2, Schemes for Sharing Systems Services and RES Integration, Mediterranean Project I, Med-TSO. Available online: http://www.med-tso.com (accessed on 1 June 2020).

46. Leal-Arcas, R.; Grasso, C.; Ríos, J.A. Multilateral, regional and bilateral energy trade governance. Energy Secur. Trade EU 2016, 6, 54-148. [CrossRef]

47. International Energy Agency. Integrating Power Systems Across Borders; Organisation for Economic Co-Operation and Development (OECD): Paris, France, 2019.

48. Italy-Tunisia Interconnector. Available online: https://www.terna.it/en/projects/projects-common-interest/ italy-tunisia-interconnection (accessed on 15 June 2020).

49. H2020, The CoordiNET Project. Available online: https://coordinet-project.eu/ (accessed on 1 July 2020).

50. H2020, The CROSSBOW Project. Available online: http://crossbowproject.eu/ (accessed on 1 July 2020).

51. Kouveliotis-Lysikatos, I.; Hatziargyriou, N.; Liu, Y.; Wu, F. Towards an Internet-Like Power Grid. J. Mod. Power Syst. Clean Energy 2020. [CrossRef]

52. Ghiani, E.; Galici, M.; Mureddu, M.; Pilo, F. Impact on Electricity Consumption and Market Pricing of Energy and Ancillary Services during Pandemic of COVID-19 in Italy. Energies 2020, 13, 3357. [CrossRef]

53. ENTSO-e, ENTSO-E Pledges for a Climate-Neutral, Resilient and Innovative European Economic Recovery, press release, July 3, 2020. Available online: https://www.entsoe.eu/news/2020/07/03/entso-e-pledges-for-aclimate-neutral-resilient-and-innovative-european-economic-recovery/ (accessed on 3 July 2020).

54. ENTSO-e. ENTSO-e Roadmap for a Multi-Sectoral Planning Support; Technical Report; ENTSO-e: Brussels, Belgium, 2020.

55. ENTSO-e and ENTSO-g. TYNDP 2020 Scenario Building Guidelines; Technical Report; ENTSO-e: Brussels, Belgium, 2020.

(C) 2020 by the authors. Licensee MDPI, Basel, Switzerland. This article is an open access article distributed under the terms and conditions of the Creative Commons Attribution (CC BY) license (http://creativecommons.org/licenses/by/4.0/). 